\title{
Stitching a torn system
}

Deciding to cut budgets is a difficult choice to make and may raise ethical issues. When faced with such a fact of life one needs to prioritise allocation of resources in a just way.

\section{WHY TO CUT?}

Cuts in budgets are inevitable in a world where the population increases and productivity does not match demands, and/or we mismanage available resources. In Lebanon these three factors have a bearing on the health of the majority of the Lebanese people. In a meeting between the Lebanese Ministers of Health and Finance on 31 December 2009, the former did not get the budget he asked for (do not misunderstand me; he did not get more). Mismanagement of resources is a universal issue. The unavailability of generics in developing countries is a big problem. ${ }^{1}$ Physicians inflate the medical bill by not adhering to evidencebased medicine and ethical guidelines. ${ }^{2,3}$ Ordering unnecessary tests is not unusual; even in emergency departments in academic institutions ordering a CRP test appears to be universal in patients presenting with fever at a time when the evidence for this practice is poor. Drug representatives in Lebanon have open access to physicians. The drug industry effect results in the prescribing of expensive medications. ${ }^{4}$ Lack of planning inflates health expenditure in Lebanon. The country is oversaturated with physicians; one doctor per 300 inhabitants; sub-specialists constitute $70 \%$ of registered medical doctors; there are 22 open heart centres, 38 magnetic resonant imaging centres and eight linear accelerator centers for a population of 4 million.

\section{WHAT TO CUT?}

The Lebanese state finances six independent governmental health funds. Each fund has its own administration. Unifying administrative procedures under one organisation allows substantial cuts on expenses.

There are 3.8 hospital beds per 1000 inhabitants in Lebanon with an occupancy rate of $56 \%$. There are around $27 \mathrm{CT}$ and 10 MRI scanners per million inhabitants in Lebanon - compared to 12 and six in Canada respectively. ${ }^{5}$ High availability of scanners may result in unindicated use of these machines. There is a need to limit spending on hospital beds and high-tech diagnostic machines.
The Ministry of Health allocates $53 \%$ of its budget on drugs to provide medicines for chemotherapy. Cutting this figure is justifiable; there is no benefit of chemotherapy in several malignant conditions, mainly those with metastasis. ${ }^{6}$ The Lebanese population consumes medicines that cost $£ 250$ million a year. Generics constitute only $2 \%$ of the pharmaceutical market. Policy makers in Lebanon can offset the reduction in the budget by enforcing the use of generic drugs.

The presence of 22 open heart centres implies there are medically unnecessary operations. There is a large debate on the choice of revascularisation procedures with more evidence-favouring angioplasty versus coronary artery bypass graft (CABG). ${ }^{7}$ Moreover, Morrison et al reported that aggressive treatment of risk factors and medical therapy result in better outcomes than CABG at a lower cost. ${ }^{8}$

Stitching a torn system due to an inattentive manager (those running the monetary system) does not justify the actions of the administrator (government). It is so disappointing to see governments penalise ordinary taxpayers and reward

\section{Protecting time}

\section{WHY SHOULD CUTS BE MADE?}

Because the level of government debt is unacceptable and will become an increasing burden to succeeding generations: it is an issue of intergenerational justice.

\section{WHAT SHOULD NOT BE CUT?}

The time that clinicians - nurses, doctors, therapists - have available to spend with patients. Why? More time means that doctors and other clinicians have more time to listen to patients and are more likely to arrive at a genuine understanding of the patient's predicament, and thereby a more accurate diagnostic formulation. More time means that the focus of the consultation is more on the person and less on the disease. More time means that patient and clinician are more likely to be able to work together in agreeing treatment plans that take account of the patient's preferences, values, and aspirations. All of these are known to improve the cost-effectiveness of health care.

Resources for research, teaching, and learning. Why? Because this is the future of medical science and health care.

\section{WHAT SHOULD BE CUT?}

The ever-increasing superstructure of monitoring, surveillance, and inspection within the health service. Why? Because there is no evidence of benefit, let alone cost-effectiveness. Poor practice continues to be exposed despite the burgeoning bureaucratic burden of multiple reporting and inspection.

The market in health care contracting. Why? Because the transaction costs cannot be justified in terms of improved services and any exposure to market forces exacerbates health inequalities.

The prodigiously expensive use of private management consultancy firms. Why? Because, yet again, there is no evidence of cost-effectiveness and much of the advice has proved misplaced and damaging.

In a universal healthcare service funded through taxation and based on social solidarity, the needs of the sick should be 
monetary institutions that mismanage the nations' wealth.

\section{Bassem Saab and Jumana Antoun}

\section{Acknowledgement}

We like to thank Doctor Rasha Hamra from the Ministry of Health for providing us with valuable data.

\section{REFERENCES}

1. Cameron A, Ewen M, Ross-Degnan D, et al. Medicine prices, availability, and affordability in 36 developing and middle-income countries: a secondary analysis. Lancet 2009; 373(9659): 240-249.

2. Zinner DE, Bjankovic D, Clarridge B, et al. Participation of academic scientists in relationships with industry. Health Aff (Millwood) 2009; 28: 1814-1825.

3. Forgacs I, Loganayagam, A. Overprescribing proton pump inhibitors. BMJ 2008; 336(7634): 2-3.

4. Saab B. Health for All? Dream On! Br J Gen Pract 2009; 59(558): 55.

5. Ariste R, Fortin G. Could MRI and CT Scanners be operated more intensively in Canada? Healthc Policy 2007; 3(1):e113-e120.

6. Segelov E. The emperor's new clothes - can chemotherapy survive? Aust Prescr 2006; 29: 2-3.

7. Park SJ, Park DW. Percutaneous coronary intervention with stent implantation versus coronary artery bypass surgery for treatment of left main coronary artery disease: is it time to change guidelines? Circ Cardiovasc Interv 2009: 2(1): 59-68.

8. Morrison D. PCI versus CABG versus medical therapy in 2006. Minerva Cardioangiol 2006: 54(5): 643-672.

DOI: 10.3399/bjgp10X483715

consistently prioritised over the demands of the well.

\section{Iona Heath}

\section{f... it is an \\ issue of \\ intergenerat- ional justice.}

\section{How to cut NHS spending and improve the health of the nation}

The immediate response of all the major political parties to the current crisis of public expenditure is to reassure the public that the NHS will be protected from the scale of spending cuts considered essential in other areas of the public sector. This is unfortunate because it is readily apparent, not only that vast resources are wasted in the NHS, but that much health service expenditure is more likely to make people ill than improve their health.

In The Rise and Fall of Modern Medicine, GP and writer James LeFanu exposed the malign influence of 'risk factor epidemiology' on public health and proposed a radical solution:

'The simple expedient of closing down most university departments of epidemiology could both extinguish this endlessly fertile source of anxietymongering while simultaneously releasing funds for serious research."

In the decade since LeFanu's book was published, increasingly authoritarian and intrusive health promotion and disease prevention campaigns based on dubious epidemiology have become a major focus of government expenditure and medical intervention (not least in primary care). The current crisis provides the ideal opportunity to implement LeFanu's proposal - and to extend its scope to the wider world of public health.

The great swine flu pandemic provides an apt symbol of resources wasted in the cause of scaremongering based on dodgy epidemiology. This follows the panics over AIDS, mad cow disease, SARS and bird flu in generating bloated bureaucracies consuming millions while provoking public anxieties out of all proportion to real risk. According to Labour MP Paul Flynn, more than $£ 1$ billion has been spent on pandemic preparations since 2005, including the purchase of 1.1 million courses of largely unused (and largely useless) antivirals, which he has suggested 'would be great for gritting the icy roads'.

In the same week that Flynn warned parliament of the dangers of crying wolf over pandemics, another parliamentary committee condemned the Chlamydia testing programme overseen by the Health Promotion Agency and implemented by primary care trusts as 'inefficient and wasteful'. ${ }^{3}$ This campaign could also stand as a symbo of numerous health promotion initiatives over the past decade.

It seems that almost very week a new report is published proclaiming that some familiar target of public health propaganda has reached epidemic (if not pandemic) proportions: alcohol consumption, obesity, drug abuse, domestic violence, teenage pregnancy. The familiar response proclaimed by politicians and medical entrepreneurs, and dutifully endorsed by the media, is that we need to devote even more resources to the sort of health promotion campaigns that have failed to prevent these problems from reaching such threatening proportions over the past decade. The sensible response, encouraged by the new climate of fiscal austerity (not to mention the unreliability of the claims for the scale of these problems), would be to abandon all these programmes and to stop throwing good money after bad.

Although I am reluctant to suggest any further structural reforms in the NHS, the abolition of PCTs looks a promising way of saving money and improving primary care at a stroke. Now that the PCTs seem to exist largely to transmit public health propaganda from the government to local services and to 'roll out' the latest fashionable initiative from the Department of Health, I don't think we would miss them. And while taking the axe to epidemiology departments, perhaps the auditors could take a look at academic departments of general practice. What are they good for?

\section{REFERENCES}

1. LeFanu J. The rise and fall of modern medicine. London: Little Brown, 1999.

2. Kmietowicz Z. Use leftover Tamiflu to grit icy roads, MP suggests. BMJ 2010; 340: c501.

3. Mooney H. England's chlamydia screening programme is patchy and inept. BMJ 2010:340: c539.

DOI: 10.3399/bjgp10X483733 